\title{
Spain, Germany, and the Holocaust: Uniting Global Learning and Student Philanthropy through Transdisciplinarity
}

\author{
Kajsa C. Larson \\ Department of World Languages and Literatures, Northern Kentucky University, Highland Heights, USA \\ Andrea Fieler \\ Department of World Languages and Literatures, Northern Kentucky University, Highland Heights, USA
}

\begin{abstract}
While the atrocities of the Holocaust have been well documented, this catastrophic event has been commonly studied through the lens of a single discipline. In a course co-taught by German and Spanish professors in conjunction with the 70th anniversary of the liberation of WWII concentration camps, advanced students of German and Spanish at Northern Kentucky University engaged with this topic by analyzing, comparing, and contrasting the German-Dutch (Anne Frank) and Spanish-French (Jorge Semprún) experience. To deepen students' cross-collaboration, the two classes engaged in a philanthropy project called the Mayerson Student Philanthropy Project. The class received a \$2,000 grant, researched and advocated for local nonprofits that addressed topics related to the Holocaust, and collectively decided on the final grant recipient. This article discusses the course structure, objectives, and outcomes of a transdisciplinary approach to literature, along with student feedback about the experience.
\end{abstract}

Index Terms — Spanish, German, transdisciplinary, student philanthropy

\section{INTRODUCTION}

Transdisciplinary pedagogy has been examined through a variety of lenses, as a way to restore and strengthen connections between academic disciplines that have weakened over time (Hyun, 2011; Dey, Ott, Antonaros, Barnhardt, \& Holsapple, 2016; Williams, Berger, McClendon, 2005). Whitehead (2016) stated that transdisciplinarity is a vehicle to meet future employers' expectations for graduates to "cooperate, to wrestle with diverse perspectives, and to build capacity to solve unscripted problems" (p. 1). Scholars such as Hyun (2011) as well as Stock and Burton (2011) have offered a variety of definitions of transdisciplinarity, as well as suggestions for how it can be integrated into the curriculum; however, more examples regarding practical classroom application of this approach are necessary.

At Northern Kentucky University (NKU), students of German and Spanish in an advanced-level literature course jointly studied the topic of the Holocaust and explored connections between the disciplines through a service-learning project, called the Mayerson Student Philanthropy Project (MSPP). Throughout the course, students examined and assessed five important global themes related to the Holocaust - emigration and displacement, sites of memory and historical testimony, artistic representation and catharsis, human rights, hunger and disease - and their portrayal in fictional and nonfictional Holocaust accounts, while simultaneously investigating nonprofits that address these same issues in the local community. At the end, through a class vote, students chose two nonprofits and awarded each with a $\$ 1,000$ grant. Additionally, students completed a survey to measure the effects that global learning and transdisciplinary study had on their cultural awareness, interest in foreign language learning, and community engagement in the context of student philanthropy. Survey results from students enrolled in the class reveal that the combined German-Spanish perspective improved students' historical understanding across borders, and empowered them to be more civic-minded and engaged. This project can serve as a means to developing high-quality global learning that includes "multiple opportunities for analysis from different perspectives and a real-world context for applying the knowledge and skills they have gained" (Whitehead, 2016, p. 1). The inclusion of the MSPP in the Spanish/German course offered students a shared experience and a chance to engage in a discussion of Holocaust-related topics, while also improving and understanding the real-world implications of the Holocaust in the twenty-first century.

For several decades, higher education has been reflecting on what constitutes a well-rounded education. In today's job market, students need to be able to do more than simply interact with individuals from different backgrounds and cultures. Indeed, students need preparation to explore, analyze, and attempt to solve the big societal challenges of today and tomorrow, challenges that are global in nature-including climate change, food and water security, global health, human rights, migration, sustainability, and technological innovation (Whitehead, 2016, p. 1).

With this in mind, students also need to have a historical understanding in order to ask appropriate questions, which allows them to confront these issues. The article begins by describing transdisciplinarity and community engagement in a global context, then the methods employed will be discussed and the results, followed by the conclusion. 


\section{TRANSDISCIPLINARITY AND COMMUNITY ENGAGEMENT IN A GLOBAL CONTEXT}

Transdisciplinarity is a tool to achieve high-impact practices (HIPs) on a local and global scale. Similar to Kuh's findings (AAC\&U, 2008, 2013), Fink (2016) identifies five HIPs, which assist in "helping students become metalearners, learning-centered course design, using small groups in a powerful way, service-learning/community engagement - with reflection, and being a leader with your students" (p. 3). Global learning discusses US diversity and world cultures while taking into account multiple perspectives. Similarly, according to Jean Piaget, who coined the term in 1970, transdisciplinarity "attempts to understand the current world with an imperative overarching unity of knowledge" (Hyun, 2011, p. 8). Stock and Burton (2011) listed an extensive collection of terms found when considering transdisciplinarity. Among them are "collaborative, integral, integrated, complementary, combined, participatory, transepistemic, system-oriented, transprofessional, comprehensive, problem oriented, cross-boundary, holistic, multidisciplinary, crossdisciplinary, interdisciplinary, and transdisciplinary" (p. 1094). In more detail, Hyun (2011) defined transdisciplinarity as follows:

Transdisciplinarity is a principle for unity of knowledge beyond disciplines, and its approach implies full interaction between, among, and beyond disciplines from a real-life problem-based perspective. Transdisciplinary vision is also transcultural and transnational, encompassing ethics, spirituality, and creativity (p. 8).

Hyun's (2011) description is closely related to the definition employed by NKU depicting transdisciplinarity as a process, which "stimulates collaborations that integrate and transcend separate disciplinary perspectives around a big problem, idea, or theme" ("Fuel the Flame," 2013). Additionally, NKU's strategic plan includes community engagement as follows: "Engage with community partners to catalyze regional growth and vitality" ("Fuel the Flame," 2013). The article at hand employs the defining lines of Hyun (2011) as well as NKU and attempts to further connect these transdisciplinary "islands of innovation" (Williams, Berger, \& McClendon, 2005, p. vii).

Keeping in mind the ideas behind transdisciplinary pedagogy, global learning, and HIPs, service learning is a way to address some of the targeted goals of interaction among disciplines "from a real-life problems perspective" including collaboration around a big problem, idea, or theme (Hyun, 2011, p. 8). Community engagement has been a way to increase students' civic participation and global awareness. The interest in these two objectives has been growing, as shown by the creation, of the Carnegie Foundation "Community Engagement" classification in 2005, which is currently managed by Brown University's Swearer Center for Public Service ("Brown University,” 2018). Today, there are 361 higher education institutions with this designation ("Brown University," 2018). Twenty-first century scholarship has also reconfirmed the benefits of, and interest in, community engagement pedagogy as a way to address big-picture, socially minded problems.

In the realm of foreign language studies, scholars have turned to community engagement because it assists in "meaningful language growth," and "cultural competence" as well as in the promotion of the practical applications of learning another language (Ebacher, 2013, p. 398; Lear \& Abbott, 2009; Caldwell, 2007). In some instances, involvement with the community may also increase students' motivation to learn a foreign language (Morris, 2001, p. 244). In line with Ebacher (2013), community engagement can offer a much broader appreciation for civic engagement and teach students about democracy and the vital life skill of being an active citizen as well as an advocate for global social concerns.

Boyte (2004) and Colby et. al (2003), who have studied the millennial generation born between 1978 and 2000 , have observed "diminished civic attachment" among this population. Millennials display a greater interest in individualism (Boyte, 2004, p. 77; Colby et. al, 2003, p. 7). Nonetheless, a study by Southgate (2010) concluded that college-age students have a strong interest in both volunteerism and cross-generational dialogue to solve problems in the community (p. 3). Thus, there is value in offering consistent community engagement or service opportunities throughout undergraduate programs as a way to fulfill students' desire to be proactive in responding to social needs in local and international arenas.

With regards to the value of service-learning opportunities, service learning is an innovative classroom approach commonly linked to community engagement, and this component relies on two main ideas: 1) reciprocity among students, faculty, community members, and educational institutions to achieve a common objective, and 2) a critical reflection component to produce and record meaningful learning and service outcomes (Felten \& Clayton, 2011, pp. 7778).

Finally, philanthropy is another approach to community engagement and is defined by a one-way transaction of resources to a recipient organization (Briggs, Yang, Harmon-Kizer, \& Arnold, 2016, p. 111). Philanthropy and service learning differ in that the former provides monetary support to community partners while the latter may provide more hands-on support such as fundraising, volunteerism, or other contribution. Fig. 1 below provides a visual overview of the intersections of the above-mentioned components with the course project: 


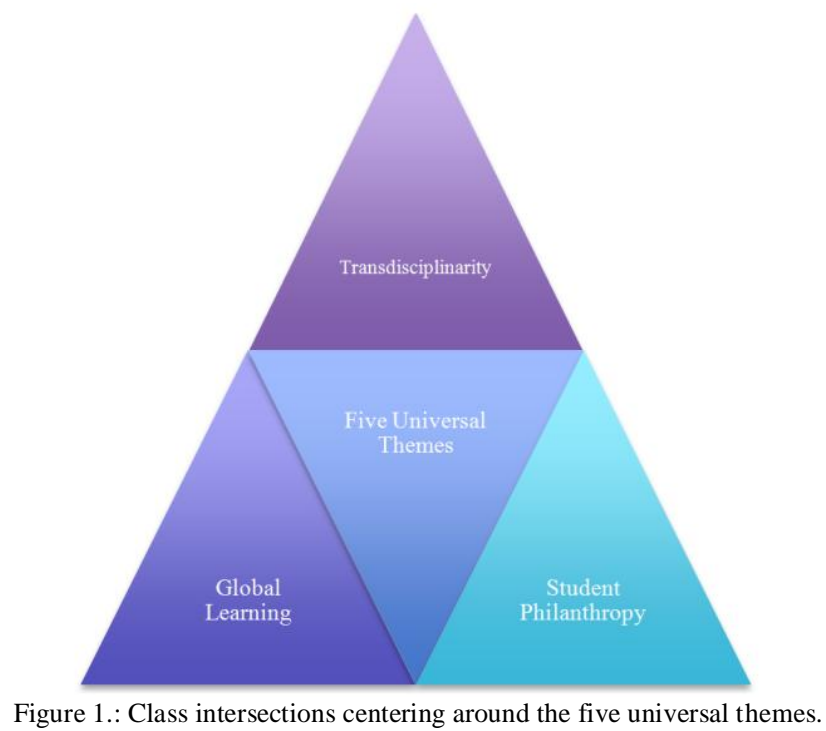

Keeping the aforementioned in mind, the study aimed to measure the compatibility of transdisciplinary learning with cultural as well as language learning and community engagement. Students completed a post-survey and answered the following questions:

- Was transdisciplinary study a positive experience?

- Did transdisciplinarity make students more culturally aware or culturally sensitive?

- Did transdisciplinary study influence students' desire to learn another foreign language?

- Does student philanthropy have a positive impact on transdisciplinary study?

- Did the Mayerson Project impact students' interest in social activism, volunteerism, civic engagement, or student philanthropy?

- What is the overall impact of incorporating a student philanthropy project in a college course?

The following section will present the methods and layout of the class.

\section{METHODS}

The course was co-designed to offer Spanish and German students a transdisciplinary class with a thematic focus on the Holocaust in the context of the 70th anniversary of the liberation of WWII concentration camps. The course examined the impacts, implications, and recollections that the Holocaust had across European countries. SPI/GER 481: "Repression, Resistance, and Reflections," is required for German and Spanish majors as an advanced literary study course. The topic varies from semester to semester and, thus, students can enroll in the course more than once. As a prerequisite, students must have completed at least one 300-level course. The two courses were not cross-listed, but instead were two separate sections offered at the same time of day. This gave the option for both classes to meet as an entire group or to meet separately. 22 students were enrolled in SPI 481 and 13 students were enrolled in GER 481. The class met three times per week for 50-minute sessions over 16 weeks. 16 sessions were co-taught by the two professors and for 29 of the sessions, the classes met separately. As a large group, class was conducted in English. On the days that the classes were not held together, students engaged in discussion and lecture in their language of study.

The instructors chose two primary texts that represent the German-Dutch and Spanish-French point of view: The Diary of Anne Frank and The Long Voyage by Jorge Semprún. Students read these texts in their respective language of study. To further bring together the ideas in these texts, students also read and watched some historical accounts about the Franco-Hitler connection, the 2000 PBS show The Trials of David Irving, a Holocaust denier, and information about the Spanish Civil War and its connection to World War II. Students also read theoretical works about testimony, Pierre Nora's lieux de mémoire (sites of memory), human rights, catharsis, and enlightenment.

In the Spanish and German sections, students further united through a philanthropic component via the MSPP. This campus-wide initiative was first implemented in 2000 at NKU (The Mayerson Annual Report, 2011/2012, p. 4). On average about 10 classes have been invited to participate per semester. Each Mayerson class is given a $\$ 2,000$ grant and students in those classes are asked to select, research, and evaluate nonprofits (501c3 organizations, government agencies, or public schools) that have specific missions, or that offer services related to the course content and the social needs being studied. Toward the end of the semester, students collectively vote to invest the money in one or two nonprofits, so the minimum award amount given to a nonprofit is $\$ 1,000$. The funding comes primarily from the Manuel D. \& Rhoda Mayerson Foundation.

The SPI/GER 481 classes were counted as one Mayerson class, and used the philanthropy project to study the connection between Holocaust-related themes and the persistence of these same needs in the local community today. The five Mayerson themes were: 1) emigration and displacement, 2) sites of memory and historical testimony, 3) 
artistic representation and catharsis, 4) human rights, and 5) hunger and disease. These aspects were chosen not only to show their historical meaning in context of the Holocaust, but simultaneously to connect their sustained legacy to local and global communities today in a real-world setting.

The SPI/GER 481 course outcomes, as listed on the syllabus, were to enable students to explain the international implications of the Holocaust, as well as the theoretical underpinnings of topics such as emigration, displacement, commemoration, testimony, and human rights. Successful students would also advance further in their language of study in the realms of reading, writing, listening, and speaking. Listed separately on the syllabus, the Mayerson outcomes were to educate students more about civic engagement, gain awareness of social problems and nonprofit organizations in the local community, and increase their knowledge of philanthropic processes such as grant seeking and grant making. Lastly, students built upon their critical thinking, communication, leadership and other work/real-life skills.

Students' grades were assessed in the following ways:

- Class Participation and Attendance: $25 \%$

- Diary: $25 \%$

- Mayerson Student Philanthropy Project: 30\% (The first reaction paper was worth 5\%, the second was $10 \%$, and the group presentation was $15 \%$ )

- Final Essay: 20\%

For the participation component, students were given a paper folder to document their attendance, learning, and progress. After each class session, the professors provided a basic 'question of the day' about the course material that students had to correctly answer in their target language, and which assisted in tracking students' attendance, while empowering students to take full ownership of their learning experience and grade. The 1-page diary entries were due every Monday, and students handed them in through their folders. The diary entries were written in the language of study and the professors provided grammatical feedback. The final exam, also written in the language of study, was a take-home essay that required students to incorporate a selection of readings studied throughout the course. For example, during the Anne Frank unit, students read a common selection of diary entries and were given comprehension questions to complete that focused on topics such as the progression of information of the diary material, Anne Frank's personal aspirations and her legacy. Anne Frank was of German nationality, however, she wrote in Dutch. The professors also purchased two models of the Anne Frank house (the Annex) to assemble as a class. At the end of this unit, the class read Pierre Nora's article about lieux de mémoire (sites of memory) to discuss how the diary dialogues with this theory. For the unit on Semprún, the students discussed the notion of identity. Semprún, a Spanish citizen, spent most of his adult life in France and wrote his novel in French. The fictional account, heavily influenced by the personal experiences of the author, traces the journey on a train to a concentration camp. Similar to the Anne Frank unit, the professors incorporated creative exercises such as poetry writing and drawing into the class lessons in order to help students link the past to the present as well as reflect on individual experiences.

As a follow-up to the course content, the professors arranged to bring Werner Coppel, a Holocaust survivor, to class as a guest speaker. At the end of the course, the class visited a special exhibit at Cincinnati's National Underground Railroad Freedom Center, called "Unlocking the Gates of Auschwitz 70 Years Later." This last activity brought together the concepts studied throughout the class, ranging from first-hand accounts of atrocity to how these memories have been preserved.

To complement the class learning outcomes, the MSPP was included so students could explore how topics related to the Holocaust persist in our own communities. The process of selecting and awarding the $\$ 2,000$ grant follows several core procedures across the disciplines at NKU. First, the instructor must connect the course content to social need, or needs, that students can discuss as well as research outside of class. Second, students split up into small groups, often called "community boards," and research one of the social needs and the nonprofits in the area that service this need. Third, the community boards identify the nonprofit, related to their social need, that they find most compelling (and also select one as a runner-up) to further investigate. One group member contacts the selected agency and invites the agency to participate in the MSPP. Fourth, students are required to conduct a site visit to the chosen nonprofit or, in some instances, complete twenty hours of volunteer work with the organization. Thus, the MSPP has the potential to be considered both a community engagement project, through a site visit, or a deeper form of service learning, through logged volunteerism, depending on how the professor integrates it into the course.

In the last stages of the project, the goal was to gather information as well as materials and reflect upon them to prepare a persuasive presentation to the rest of the class. The purpose of the presentation is to synthesize the information about the course content with students' observations and experiences in relation to their chosen nonprofit. In most cases, the community boards want to persuade the class that their chosen organization deserves the $\$ 2,000$ grant. The process is shown in overview in Fig. 2 below. 


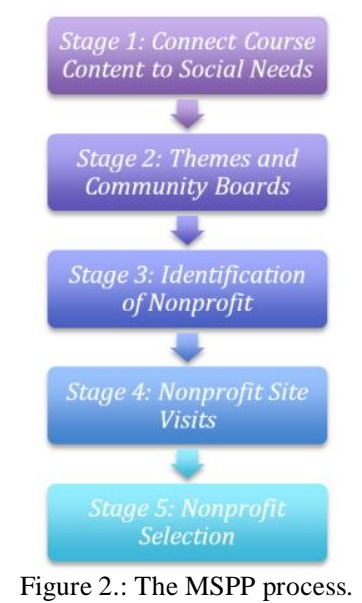

An award ceremony is held at the end of each semester in which professors and some students from Mayerson classes convene with representatives from the chosen nonprofits to present the grant awards. At this time, professors, students, and nonprofit representatives reflect upon, and most importantly celebrate, the positive impact of the Mayerson experience.

Since the SPI/GER 481 class was a larger group (35 students), the professors adapted the Mayerson model to better suit the class needs. The following timeline was built into the syllabus of the 16-week course:

Week 1: Students reviewed five social themes that connected the course content to the Mayerson Project: emigration and displacement, sites of memory and historical testimony, artistic representation and catharsis, human rights, and hunger and disease. Each person was asked to pick two topics that interested him or her.

Week 2-Week 5: The class was divided into five groups ("community boards") based on the aforementioned themes. There were 7 students per group. Each group had to include both German and Spanish students. As homework after class, students began preliminary internet research about the group's assigned theme in order to prepare a 2-page report, written in the target language, that required students to synthesize the course content and community connections by answering the following questions:

1) How does this theme connect to Spain/Germany and the Holocaust? What types of social problems or needs are associated with this theme? Cite specific examples from research on the internet.

2) Next, do some internet research to identify the types of 501(c)3 nonprofits, public schools or government agencies in the Northern Kentucky/Cincinnati area that offer services related to your theme. These services do not have to deal directly with the Holocaust, but should correspond with some of the social needs identified in \#1. Discuss a minimum of three nonprofits and describe what they do.

3) Explain what nonprofit you find most valuable or interesting? Why?

Week 5: In class, students met in their community boards to discuss their individual reaction papers. The community boards then selected two organizations to research in depth. The groups also chose one back-up organization. At that time, each community board was split in two so that the smaller subgroups (3-4 students) could conduct a site visit to at least one of the group's two chosen nonprofits. The students had the option to attend both site visits. Two students in each community board volunteered to contact the chosen nonprofits and explain the Mayerson Project and the amount of the minimum grant award $(\$ 1,000)$ to them.

Week 5-Week 11: The community boards conducted site visits to the chosen nonprofits. The goal of these site visits was to ask questions and gather any materials (pamphlets, visuals, photos with the organization's permission) and for students to take notes. The observations were used to write the second 2-3-page reaction paper, written in the language of study, which included the following:

a) Explain in detail the site visit and your personal impressions (1-1.5 pages). This part should be written to help the professor envision what this experience was like for you (who you met, what you saw, what called your attention, what you learned, etc.).

b) How does this nonprofit relate to our course content and the Mayerson theme you are studying? When possible, cite specific examples from what you have learned throughout the semester (no "works cited" page is required). (1 page)

c) Write one paragraph that explains the agency's mission and program and how they would spend the grant money. After visiting, do you think this nonprofit deserves the grant money? Why? (1/2 page).

To address specialized language needed to describe the nonprofits, students had the option to share important statistics or information related to the nonprofits using footnotes in English.

Week 11-Week 13: Students prepared for a group presentation that took place in Week 13. The presentations lasted 15-20 minutes and were given in English. The community board presented information about the information that they gathered about the two nonprofits. They were given the following tips to prepare for a successful presentation:

a) The audience will not be familiar with your topic, so make sure to keep that in mind while preparing your presentation. Please provide basic information (such as what theme did your community board study), a general 
introduction to your community board and your assigned theme, and the films associated with it. Briefly, share information about the preliminary research on this topic. Why did you decide to research this particular nonprofit?

b) Groups should also give a general introduction to your nonprofit and its mission. What did you learn during the site visit? What was most compelling? How does this nonprofit relate to, and promote the needs of, the topic you studied? Explain.

c) When possible, the presentations should bring together information that we have studied in class and the research that you have conducted through the Mayerson Project. To receive a good grade for the presentation, community boards must synthesize class material with Mayerson research. Please refer directly to some of the readings or concepts, as well as research you have done outside of class with the Mayerson Project, to support your ideas.

d) Make sure that your presentation is convincing and persuasive if you believe that your nonprofit should receive the grant funding!

Week 13: The first two days of Week 13 were devoted to the five community board presentations. After each one, the entire class (including those who presented) voted to decide which of the group's two nonprofits was a finalist. After all of the finalists were selected, students dedicated an entire class session to vote and decide how many awards would be given to nonprofits. The class chose to give two $\$ 1,000$ awards to the emigration group's nonprofit, Centro de Amistad, and to Melodic Connections, the nonprofit from the artistic representation and catharsis group. At this time, the class also decided how to contact all of the nonprofits and present them with either a rejection or an award letter.

Week 15: The Mayerson classes across campus convened for the award ceremony to speak about their experiences and award the grant money. At the end of the course, the professors sent a two-part survey to students.

\section{DISCUSSION}

The hypotheses for the survey were that students would embrace both the transdisciplinary nature of the course and the philanthropic component of the class and become more aware and sensitive to cultural differences through the structure of the class. It was uncertain if students would feel more inclined to learn another foreign language, consider volunteerism, or become more socially active. The first part implemented a Likert scale and included a total of 17 questions. The Likert scale questions were coded with 1 as strongly disagree, 2 as disagree, 3 as no effect, 4 as agree, 5 as strongly agree. The second part included three free-response questions. The following is a breakdown of the Likertscale questions that were asked to measure the specific survey objectives, along with the results and an analysis of student responses:

Was transdisciplinary study a positive experience?

$\circ 1$ a) The cross cultural approach to the course improved my overall learning experience. $84 \%$ of students either strongly agreed or agreed with this statement, while $9 \%$ either strongly disagreed or disagreed, and $6 \%$ stated no effect.

$\circ 2 \mathrm{~d}$ ) I would not take another course with a cross-cultural component. Only $15 \%$ answered strongly agree or agree, and another $78 \%$ strongly disagreed or disagreed, while $6 \%$ stated no effect, thus suggesting that it was overall a positive experience.

The findings of these two questions show that a large majority of the class was receptive to taking another crosscultural class, thus identifying the experience as positive.

Did transdisciplinarity make students more culturally aware or culturally sensitive?

$\circ 1$ b) Throughout this course, I was able to make historical cultural connections between two separate cultures and languages. None of the class strongly disagreed or disagreed with this statement, $87 \%$ strongly agreed or agreed, and $13 \%$ stated no effect.

$\circ 1$ c) My global cultural awareness improved as a result of this course? None of the students strongly disagreed, $16 \%$ stated no effect, and $78 \%$ strongly agreed or agreed, and 6\% disagreed.

$\circ 1 \mathrm{~d}$ ) I feel more interested in learning about other cultures as a result of this course. None strongly disagreed, $10 \%$ disagreed, and $10 \%$ stated no effect. $80 \%$ strongly agreed or agreed.

$\circ 1$ e) I feel more compassionate toward other cultures as a result of this course. None strongly disagreed, $6 \%$ disagreed, $9 \%$ stated no effect. $84 \%$ strongly agreed or agreed.

A larger majority was able to identify cultural connections, both globally and locally as well as felt compassionate as a result.

Did transdisciplinary study influence students' desire to learn another foreign language?

$\circ 2$ a) I do not feel more motivated to learn a third language as a result of this course. $69 \%$ either strongly disagreed or disagreed, $15 \%$ stated no effect, while $12 \%$ strongly agreed and $3 \%$ agreed with this statement.

With regard to motivation, survey responses suggest some level of motivation to learn another foreign language.

Did transdisciplinary study impact students' interest in social activism, volunteerism, or civic engagement?

$\circ 2$ b) My perspective of social issues has not changed as a result of this course. $82 \%$ strongly disagreed or disagreed, $12 \%$ stated no effect, no one strongly agreed, but $6 \%$ agreed with this statement.

$\circ 2$ c) The course content did not enhance my desire toward social activism. $72 \%$ strongly disagreed or disagreed, $12 \%$ stated no effect, $15 \%$ agreed, while no students strongly agreed.

$\circ 2$ e) The course content did not enhance my desire toward volunteerism. $72 \%$ strongly disagreed or disagreed, $18 \%$ stated no effect, $9 \%$ strongly agreed or agreed. 
$\circ 3 \mathrm{~b})$ The course content enhanced my awareness of social needs, especially those related to the topics that the class researched through the Mayerson Project. 88\% strongly agreed or agreed, 9\% stated no effect, and 3\% disagreed, while no students strongly disagreed.

Students indicated some impact on their social activism and awareness of social issues and this points to a desire to be more socially active as a result of the course.

Does student philanthropy have a positive impact on transdisciplinary study?

$\circ 3$ a) The Mayerson Project enhanced my understanding of the topics we studied in this course. $81 \%$ strongly agreed or agreed, $12 \%$ stated no effect, $3 \%$ disagreed, and 3\% strongly disagreed with this statement.

With regard to the Mayerson Project, there were similar percentages of students who agreed that the philanthropy project had a positive impact on transdisciplinary study while also positively influencing students' activism.

What is the overall impact of incorporating a student philanthropy project in a college course?

○ 3 c) The Mayerson Project enhanced my awareness of social needs, especially those related to the topics that the class researched through the Mayerson Project. 97\% strongly agreed or agreed, 3\% stated no effect, and no one strongly disagreed or disagreed with this statement.

Overall, students agreed that the philanthropic component contributed to their awareness of social needs with a total of $97 \%$ either strongly agreed or agreed while $72 \%$ of students either strongly agreed or agreed, that the transdisciplinary nature of the course impacted their heightened awareness of social needs.

The free-response comments provided by students allowed for greater insight into their experiences. The freeresponse questions are listed below along with selected student comments.

How did the cross-cultural approach to the course affect your language learning?

1. "It was really cool for me to be able to compare certain words and phrases with the German students. I loved being able to interact and become friends with students I wouldn't have known and learning about the cultures we are studying together."

2. "Overall, I became interested in learning languages. Watching Dr. Larson and Dr. Fielder [sic] interact with each other with the two languages was a good learning experience. The connections were there and useful. With regards to Spanish specifically, it didn't affect a large portion of my language learning."

3. "The combination with the German class did reduce the amount of Spanish used in the class, but it gave me the opportunity to learn about the language and culture. I have wanted to learn German for many years and this gave me the opportunity to hear and learn about the language and help keep that desire alive. I also learned about the German culture through the class experiences with the German professor."

How did the cross-cultural approach to the course affect your cultural learning?

1. "It really shows that there isn't a stark line between cultures and history, they all intermix."

2. "It helped to understand social issues around the world and how we can become activists."

3. "I think it is important when learning about cultures, history, etc. to learn about them through a wider perspective. Often we are taught about a culture through a narrow perspective, that is to say that for example just learn about one country. But I think it is important to understand a culture/time period in relation to other countries, themes, etc. This sort of learning broadens our knowledge, and I really enjoyed that about this class."

Did the Mayerson Project adequately complement the cross-cultural approach to this course? Explain.

1. "With the different themes, it helped me expand my view of nonprofits. It also provided good connections to the cross cultural class. The mayerson [sic] project enhanced the cross-cultural approach."

2. "Yes it did! It went well with the 5 themes discussed in class and the entire class was able to easily connect it back to our texts (which came from two different cultures in a way), and the presentations related to a wide variety of cultures and groups (hispanic [sic] community, the economically disadvantaged, etc.)."

3. "Yes, the Mayerson Project deepened my knowledge of other cultures (not just ethnic cultures) and gave me a chance to understand where other people's lives have taken them."

If your perspective of social issues has changed as a result of this course, please explain how?

1. "I am more interested in new organizations as a result of this project. I often have a biased prejudice that people in need have done something wrong to put them in that position. This course has helped me be more compassionate toward many social issues and needs."

2. "It's one thing to read about social issues, and quite another to go out and see them firsthand. It was very educational in that respect."

3. "My perspective of social issues have not changed much. However, I do have a better understanding of different struggles in this area and ways I can help."

What could you have done better to make this a more successful experience?

1. "I felt that I had a very good experience so I really wouldn't have done anything differently. I had a good group and great topic that we were all passionate about. I could have thoroughly read the readings more in order to improve my reading comprehension."

2. "Nothing. Maybe put a little more time into the readings, but I fulfilled my obligation to the course and consistently felt intellectually stimulated."

3. "I think fundraising would have been a good addition." 


\section{CONCLUSION}

Offering a cross-listed class can be challenging, not only to the students, but to faculty alike. It requires planning, teamwork, open dialogue, and good communication. Overall, SPI/GER 481: "Repression, Resistance, and Reflections" successfully brought together a transdisciplinary approach with community engagement in order to create a global learning environment. The data confirms the hypotheses that students would embrace the transdisciplinary nature and philanthropic component of the class and would become more aware and sensitive to local as well as global cultural differences through the structure of the class. To some degree, students also felt that they became more socially active and more inclined to learn another foreign language. For example, one student from the Spanish section chose to enroll in German 101 the following semester.

There are, however, several possibilities for improving and developing a future course. For instance, language instruction could be incorporated into the curriculum so that students could begin to acquire a second foreign language at a rudimentary level (aka the Spanish professor teaches a micro lesson to the German class and vice versa). Furthermore, the two professors could offer targeted lectures in their areas of specialty. For instance, during the course students particularly benefited from personal photography taken of Dachau. More could have been presented in a similar fashion to deepen the personal connections to the Spanish Civil War, such as showing images of mass grave exhumations. Lastly, more academic articles on transdisciplinary study and community engagement could be assigned to students to further deepen their understanding of the course objectives. The class could also develop a blog or vlog to promote an online dialogue. Focusing on the translational aspects, it may be productive to select a few linguistically challenging passages and reflect on how to resolve the issues and to generally discuss the overall differences of the texts. This would add another layer of reflection and synthesis to both the course material and the community engagement project. It is hoped that readers of this article will also reflect upon ways of developing transdisciplinary courses with community engagement components to promote global learning while offering fun and new experiential opportunities for students.

\section{ACKNOWLEDGMENTS}

The authors wish to thank Northern Kentucky University's Scripps Howard Center for Civic Engagement, the Mayerson Student Philanthropy Project, Mark Neikirk, Filicia Share, the Department of World Languages and Literatures, and Dr. Caryn Connelly.

\section{REFERENCES}

[1] Briggs, E., Yang, Z., Harmon-Kizer, T.R., \& Arnold, T.J. (2016). How do differing community engagement strategies affect consumer responses to a retailer? Journal of Marketing Theory and Practice 24.1, 109-127.

[2] Brown University (2018). Carnegie classification. Retrieved from https://www.brown.edu/swearer/carnegie (accessed 10/10/2018).

[3] Bowen, F., Newenham-Hahindi, A., \& Herremans, I. (2010). When suit meets roots: The antecedents and consequences of community engagement strategy. Journal of Business Ethics 95, 297-318.

[4] Boyte, H. C. (2004). Everyday politics: Reconnecting citizens and public life. Philadelphia, PA: University of Pennsylvania Press.

[5] Caldwell, W. (2007). Taking Spanish outside the box: A model for integrating service learning into foreign language study. Foreign Language Annals 40.3, 463-471.

[6] Colby, A., Erlich, T., Beaumont, E., \& Stephens, J. (2003). Educating citizens: Preparing America's undergraduates for lives of moral and civic responsibility. San Francisco, CA: The Carnegie Foundation for the Advancement of Teaching.

[7] Dewey, J. (1916). Democracy and education. New York, NY: The Free Press.

[8] Dewey, J. (1927). The public and its problems. Athens, OH: Swallow/Ohio University Press.

[9] Dey, E. L., Ott, M. C., Antonaros, M., Barnhardt, C. L., \& Holsapple, M. A. (2010). Engaging diverse viewpoints: What is the campus climate for perspective-taking? [PDF document]. Retrieved from www.aacu.org/sites/default/files/files/core_commitments/engaging_diverse_viewpoints.pdf (accessed 9/13/2016).

[10] Ebacher, C. (2013). Taking Spanish into the community: A novice's guide to service learning. Hispania 96.2, $397-408$.

[11] Felten, P. \& Clayton, P. H. (2011). Service-learning. New Directions for Teaching and Learning 128, 75-84.

[12] Fink, L. D. (2016). Five high-impact teaching practices. Collected Essays on Learning and Teaching 9, 3-17.

[13] Hyun, E. (2011). Transdisciplinary higher education curriculum: A complicated cultural artifact. Research in Higher Education Journal 11, 1-19.

[14] Kuh, G. (2008). High-impact educational practices: What they are, who has access to them, and why they matter. Washington, DC: Association of American Colleges and Universities.

[15] Kuh, G. \& O’Donnell K. (2013). Ensuring quality \& taking high-impact practices to scale. Washington, DC: Association of American Colleges and Universities.

[16] Lear, D. \& Abbott, A. (2009). Aligning expectations for mutually beneficial community service-learning: The case of Spanish language proficiency. Hispania 92.2, 312-323.

[17] Levin, T. \& Nevo, Y. (2009). Exploring teachers' views on learning and teaching in the context of a trans-disciplinary curriculum. Journal of Curriculum Studies 41.4, 439-465.

[18] Morris, F. A. (2001). Serving the community and learning a foreign language: Evaluating a service-learning program. Language, Culture and Curriculum 14.3, 244-255. 
[19] Northern Kentucky University. (2013). Fuel the flame. Retrieved from fueltheflame.nku.edu/ (accessed 9/13/2016).

[20] Rhoads, R. A. (2003). How civic engagement is reframing liberal education. Peer Review 5.3, 25-27.

[21] Scripps Howard Center for Civic Engagement at NKU. (2012). The Mayerson Student Philanthropy Project Annual Report: $\begin{array}{llllll}\text { Fall 2011/Spring } & 2012 & \text { [PDF } & \text { document]. } & \text { Retrieved }\end{array}$ https://inside.nku.edu/content/dam/nkuhome/images/scripps/2011MayersonAnnualReportFINAL.pdf (accessed 9/13/2018).

[22] Southgate, S. R. (2010). Making the move from shouting to listening to public action: A student perspective on millennials and dialogue. Journal of Public Deliberation 6.1, 1-10.

[23] Stock, P. \& Burton, J. F. (2011). Defining terms for integrated (multi-inter-trans-disciplinary) sustainability research. Sustainability 3, 1090-1113.

[24] Whitehead, D. M. (2016). Integrating global learning across the curriculum for all students. Washington, DC: Association of American Colleges and Universities.

[25] Williams, D. A., Berger, J. B., \& McClendon, S. A. (2005). Toward a model of inclusive excellence and change in postsecondary institutions [PDF document]. Retrieved from www.aacu.org/sites/default/files/files/mei/williams_et_al.pdf (accessed 9/13/2016).

Kajsa C. Larson earned a Ph.D. in hispanic and lusophone literatures, cultures, and linguistics in 2010 from the University of Minnesota, Twin Cities in Minneapolis, MN. She also holds an M.A. in hispanic literature from the University of Minnesota, Twin Cities in Minneapolis, MN, which she received in 2005. She is currently an Associate Professor of Spanish and Faculty Coordinator of the Mayerson Student Philanthropy Project at Northern Kentucky University in Highland Heights, KY. In addition to publications about film and student philanthropy, she is co-author of the forthcoming third edition of the Mayerson faculty handbook for how to introduce student philanthropy in the college classroom, which can be found at https://inside.nku.edu/civicengagement/programs/mayerson.html. Her current research interests include the cultural representation of disability in Spain as well as the impact of student philanthropy on academic success.

Andrea Fieler holds a PhD in German Studies from the University of Cincinnati, United States of America, since 2009. She currently works as Lecturer of German at Northern Kentucky University, United States of America. In 2015, Dr. Fieler published her book W.G. Sebalds Nach der Natur: Eine Analyse (Bern, Switzerland: German Life and Civilization, Peter Lang). Additionally, her research interests include language acquisition and service learning. Recently, she connected language acquisition, video games as well as other digital resources, and student philanthropy. 